\title{
Uma trajetória revisitada: o pioneirismo de Maria Ignez Paulino nos estudos sobre mulheres rurais
}

Mulheres rurais: quadro décadas de diálogo.

PAULILO, Maria Ignez.

Florianópolis: EdUFSC, 2016, 383p.

Mulheres rurais: quatro décadas de diálogo, lançado em 2016 pela Editora da Universidade Federal de Santa Catarina (UFSC), de Maria Ignez Paulilo, reúne artigos publicados ao longo de sua trajetória acadêmica, iniciada na década de 1970. Doutora em Antropologia Social pela Universidade Federal do Rio de Janeiro (1987), com pósdoutorado pela The London School of Economics and Political Science (1997), Maria Ignez é professora aposentada da UFSC e, atualmente, atua como professora voluntária na mesma instituição e coordena o Núcleo de Estudos sobre Agricultura Familiar - NAF (vinculado ao Departamento de Sociologia e Ciência Política).

Além da apresentação, escrita por Eva Alterman Blay, Professora Titular Sênior da Universidade de São Paulo, a obra traz um texto de introdução e está cronologicamente organizada em quatro partes (décadas de 1976-1986; 1986-1996; 1996-2006; 2006-2016). Dos 14 artigos, dos quais cinco foram publicados em coautoria, todos fazem indicação da primeira publicação, destacando, nos casos específicos, os vínculos com as respectivas instituições de fomento e de pesquisa.

Com a coletânea, a autora possibilita a experiência privilegiada de leitura da trajetória acadêmica pioneira de uma pesquisadora brasileira que ousou transitar, interrogar e promover interlocuções com mulheres em contextos rurais plurais, por meio dos quais se produzem/reproduzem modos de vida e de trabalho. Todavia, é importante ter em mente que seguir determinada cronologia dos textos presentes no volume, organizada por décadas, no próprio dizer da autora, especificamente no que diz respeito aos dois primeiros textos (originalmente publicados na década de 1970), "[...] a razão é mais complexa do que somente o desejo de apresentar a trajetória acadêmica de uma pesquisadora." (Maria Ignez PAULILO, 2016, p. 15). Para explicitar, enuncia:

Fiel à ideia dos "vasos comunicantes", acrescento mais uma forma de fidelidade: a de que a busca por valores universais é possível. Não nego a importância da "virada linguística" do feminismo, do pósmodernismo, do desconstrucionismo e nem do multiculturalismo. São posturas críticas que ajudam a 
pôr em xeque "verdades" tidas como universais, mais eivadas de preconceitos e injustiças. Porém, daí a aceitar que a ciência é apenas uma colcha de retalhos de construções que se equivalem vai alguma distância. [...] A busca por explicações mais universais está no cerne do nascimento das ciências. Se o "universal absoluto" não existe, nem por isso o outro extremo, o "relativismo absoluto", é uma meta desejável. (PAULILO, 2016, p. 15)

A reflexão apresentada pela pesquisadora é mais ampla e o recorte objetiva dimensionar a complexidade e o rigor epistemológico que pautou a organização dos textos como coletânea. Na apresentação, além de problematizar a produção do conhecimento científico, a autora, por meio do conceito de "transmodernidade", termo cunhado por Rosa María Rodriguez Magda (2007), busca legitimar a coletânea de modo a evidenciar uma visão não "evolucionista do feminismo" e de compreensões orientadas pelas noções de superação de correntes teóricas.

Os textos, cronologicamente dispostos, dialogam com discussões contemporâneas na medida em que se verifica a interface temática mulheres rurais e trabalho, mobilizada em pesquisas realizadas em diferentes localidades geográficas e contextos rurais, dedicadas, em grande medida, à divisão sexual do trabalho e à participação de mulheres em atividades agrícolas historicamente menosprezadas, desencadeando reflexões em torno de permanências que marcam as trajetórias laborais femininas, mas que também permitem identificar a insubordinação e a resistência das mulheres, por meio da criação e da participação em movimentos sociais rurais. Nos campos dos estudos rurais e de gênero, entres outras obras que reúnem artigos sobre a temática mulheres rurais, faz-se referência aos dossiês publicados pela Revista Estudos Feministas, nos anos de 2004 e 2007, respectivamente, intitulados "As agriculturas do sul do Brasil" (organizado por Anita Brumer e Maria Ignez Paulilo, 2004) e "Mulheres em áreas rurais nas regiões Norte e Nordeste do Brasil" (organizado por Rosineide de L. M. Cordeiro e Russel Parry Scott, 2007), o livro Gênero e geração em contextos rurais (organizado por Parry Scott, Rosineide Cordeiro e Marilda Menezes, 2010).

Diante do exposto, ainda que se tenha a clareza de que as notas aqui tecidas não trazem em plenitude a potência da produção acadêmica da autora e a sua importância como intelectual competente e eticamente comprometida, na sequência, são elaboradas algumas considerações sobre os textos que integram a obra.

A Parte I apresenta os textos intitulados "O trabalho da mulher no meio rural" e "A mulher e a terra no Brejo Paraibano". Referentes às décadas de 1976 a 1986, expõem duas experiências acadêmicas de pesquisa geograficamente distintas, as quais revelam a impossibilidade do uso genérico do termo "mulher rural" e trazem a participação feminina em lidas agrícolas plurais. O primeiro texto, escrito com base na dissertação da autora, defendida em outubro de 1976 (PAULILO, 1976), apresenta o estudo realizado na área que compreende o munícipio de Valparaíso, localizado no estado de São Paulo. O segundo texto trata de uma pesquisa realizada no período de setembro de 1978 a fevereiro de 1979 , no Brejo Paraibano, estado da Paraíba, com o objetivo de "[...] levantar as condições de trabalho das mulheres de parceiros, arrendatários e assalariados, e das mulheres volantes [...] e, ao mesmo tempo, desvendar a forma de apropriação, pelo capital, do excedente por elas produzido." (PAULILO, 2016, p. 57).

Os dois textos, respectivamente intitulados "O peso do trabalho leve" e "O 'ser' e o 'deveria ser' no conceito da pequena produção" compõem a Parte ll do livro e referem-se ao período de 1986 a 1996. O primeiro, aborda sobre os estudos realizados em municípios das regiões nordeste e sul do país, que demonstram determinada divisão sexual do trabalho, instituída pelas categorias trabalho "leve" e "pesado", por sua vez atreladas ao sexo do trabalhador e a especificidades agrícolas de cada região. No segundo, mobilizada pelo 
estudo de um assentamento de reforma agrária e pela eminência de novas formas de "pequena produção", a autora problematiza e reflete sobre tal conceito e os seus limites na compreensão de realidades rurais heterogêneas.

A Parte III, de 1996 a 2006, é composta por: "O conhecimento tradicional e maricultura"; "Mulher e atividade leiteira", em coautoria com Alessandra Bueno De Grandi e Marineide Maria Silva; "Trabalho familiar: uma categoria esquecida de análise"; e "Mulheres e Eucaliptos: fertilidade e aridez", em coautoria com Iraldo Alberto Alves Matias. Guardadas as especificidades laborais, nos dois primeiros textos - sobre a maricultura e a atividade leiteira -, a autora demonstra a permanência de determinada divisão sexual do trabalho ante a novas possibilidades de produção. Em "Trabalho familiar: uma categoria esquecida de análise", a concepção de campesinato é problematizada à luz de pressupostos do marxismo e do feminismo, relevando a relação (in)tensa que se estabelece em torno da histórica primazia das demandas de classe em detrimento das demandas de gênero, manifestas, por exemplo, na agricultura familiar, pelas condições socioeconômicas desiguais e pelo não reconhecimento de direitos das mulheres, em que pesem os enfrentamentos e as lutas empreendidas por movimentos sociais de mulheres nas últimas décadas. O texto que encerra a Parte III traz para o debate as ações coletivas de mulheres, oriundas de diferentes movimentos de trabalhadores do campo, especialmente vinculadas à Via Campesina, em defesa da vida e da reprodução da agricultura familiar diante da problemática ambiental e socioeconômica agravada pelas monoculturas e pelas crescentes áreas ocupadas com reflorestamento.

A Parte IV - de 2006 a 2016 - reúne seis artigos, nos quais a autora expõe os estudos de temáticas envolvendo movimentos sociais de mulheres. Por meio deles são narradas trajetórias e diferentes reivindicações em torno de demandas por direitos e igualdade entre os sexos. Os artigos "História oral e memória: movimentos sociais de mulheres camponesas", em coautoria com Cristiani Bereta da Silva; "Movimentos de Mulheres agricultoras e os muitos sentidos da 'igualdade de gênero'”; "Intelectuais e militantes e as possibilidades de diálogo"; "Memórias e trajetórias de Luci Choinacki: histórias e lutas pelos direitos das mulheres camponesas", também em coautoria com Cristiani Bereta da Silva; "FAO, fome e mulheres rurais"; e "Movimentos de mulheres agricultoras e ecologia", em coautoria com Valdete Boni, destacam, entre outras questões a interlocução com o Movimento de Mulheres Agricultores de Santa Catarina (MMA), criado no início da década de 1980 e transformado, no ano de 2004, em Movimento de Mulheres Camponesas (MMC) e a unificação nacional referenciada remonta a uma trajetória de lutas, iniciada nos primeiros anos de 1980. Além de questões que dizem das ações coletivas na luta por direitos trabalhistas e pela igualdade de gênero, são apresentadas reflexões sobre a centralidade da participação das mulheres na produção de alimentos e na construção de um modelo de agricultura agroecológico.

Para finalizar, enfatiza-se que, pela interlocução com um sólido referencial teórico, proveniente de diferentes áreas do conhecimento, a autora realizou pesquisas e escreveu sobre experiências laborais de mulheres circunscritas por desigualdades sociais, culturais, econômicas, entre outras, o que possibilita afirmar que Mulheres rurais: quatro décadas de diálogo apresenta uma inestimável contribuição para o campo de estudos sobre mulheres em contextos rurais, na interface com os estudos de gênero e os estudos feministas.

\section{Referências}

BRUMER, Anita; PAULILO, Maria Ignez. "As agriculturas do sul do Brasil". Rev. Estud. Fem., Florianópolis, v. 12, n. 1, p. 171-174, abr. 2004. Disponível em http://www.scielo.br/ scielo.php?script $=$ sci_arttext\&pid $=$ S0104-026X2004000100009\&Ing $=$ pt\&nrm $=$ iso. Acesso em: 20/04/2017. 
CORDEIRO, Rosineide de L. M.; SCOTT, Russel Parry. "Mulheres em áreas rurais nas regiões Norte e Nordeste do Brasil". Rev. Estud. Fem., Florianópolis, v. 15, n. 2, p. 419-423, ago. 2007. Disponível em: http://www.scielo.br/scielo.php?script=sci_arttext\&pid=S0104026X2007000200008\&lng=pt\&nrm=iso. Acesso em: 14/04/2017.

PAULILO, Maria Ignez. Mulheres rurais: quatro décadas de diálogo. Florianópolis: EdUFSC, 2016.

PAULILO, Maria Ignez S. O trabalho da mulher no meio rural. 1976. 155 f. Dissertação (Mestrado em Ciências Sociais Aplicadas) - Universidade de São Paulo, São Paulo, 1976.

RODRIGUEZ MAGDA, Rosa María. "El placer del simulacro: feminismos y transmodernidad". In: FEMENÍAS, María Luisa. Perfiles del feminismo iberoamericano. v. 3. Buenos Aires: Catálogos, 2007, p. 139-160.

SCOTT, Parry; CORDEIRO, Rosineide; MENEZES, Marilda. Gênero e geração em contextos rurais. Florianópolis: Mulheres, 2010.

[Recebida em 22/04/2017

e aprovada em 30/09/2017]

Giovana Ilka Jacinto Salvaro Universidade do Extremo Sul Catarinense, Criciúma, SC, Brasil

Giovana Ilka Jacinto Salvaro (giovanailka@gmail.com) é mestra em Psicologia e doutora em Ciências Humanas pela Universidade Federal de Santa Catarina (UFSC), professora do Programa de Pós-Graduação em Desenvolvimento Socioeconômico e do Programa de Pós-Graduação em Direito da Universidade do Extremo Sul Catarinense UNESC.

4 Revista Estudos Feministas, Florianópolis, 26(2): e50188 